\title{
SEAWATER DESALINATION USING AIR GAP MEMBRANE DISTILLATION - AN EXPERIMENTAL STUDY ON MEMBRANE SCALING AND CLEANING
}

\author{
Duong Cong Hung ${ }^{1,}$, Luong Trung Son ${ }^{2}$, Pham Manh Thao ${ }^{2}$, Huynh Thai Nguyen² \\ ${ }^{1}$ Strategic Water Infrastructure Laboratory, School of Civil Mining and Environmental \\ Engineering, University of Wollongong, Wollongong, NSW 2522, Australia \\ ${ }^{2}$ School of Environmental Engineering, Faculty of Physics and Chemical Engineering, \\ Le Quy Don Technical University, 236 Hoang Quoc Viet, Cau Giay, Hanoi, Viet Nam \\ "Email: hungcd@uow.edu.au
}

Received: 7 September 2016; Accepted for publication: 28 December 2016

\begin{abstract}
The connection between operating temperature and membrane scaling/cleaning during an air gap membrane distillation (AGMD) process of seawater has been systematically elucidated in this study. Experimental and mathematically simulated data demonstrate the profound influences of feed salinity and membrane scaling on water flux at various operating temperatures. Feed salinity exerted significant impacts on water flux at high operating temperatures because of aggravated polarization effects. Membrane scaling and the subsequent membrane cleaning efficiency were also strongly affected by operating temperatures. Indeed, membrane scaling was more severe and occurred at a lower water recovery when operating at $60-50{ }^{\circ} \mathrm{C}$ (feed-coolant temperature) compared to that at $35-25{ }^{\circ} \mathrm{C}$. Moreover, membrane cleaning with fresh water and vinegar was less effective for the membrane scaled at $60-50{ }^{\circ} \mathrm{C}$ compared to $35-25^{\circ} \mathrm{C}$. Finally, membrane cleaning using vinegar was much more efficient than fresh water. Given the availability of vinegar at household level, vinegar cleaning can potentially be a low cost and readily accessible approach for MD maintenance for small-scale seawater desalination applications in remote coastal communities.
\end{abstract}

Keywords: membrane distillation, air gap membrane distillation, membrane scaling, membrane cleaning, seawater desalination.

\section{INTRODUCTION}

Seawater desalination is a practical approach to secure drinking water supply for small and remote coastal communities around the world [1]. Large-scale seawater desalination using reverse osmosis (RO) and conventional thermal distillation such as multi-stage flash (MSF) has been effectively implemented to provide freshwater for large and centralized communities. Indeed, RO desalination requires a pressure of about 60 bar (hence the need for high-pressure pumps and duplex stainless steel materials), intensive pre-treatment, and skilled operators. On the other hand, MSF demands a large physical and energy footprint. As a result, both RO and 
MSF desalination are not applicable for small and remote areas. Freshwater provision for these areas requires an alternative desalination process that can negate all the above drawbacks inherent in RO and MSF technologies.

Membrane distillation (MD) is a combination of conventional thermal distillation and a membrane separation process. MD utilizes a hydrophobic, microporous membrane as a physical barrier for separation and a temperature gradient across the membrane as the driving force for mass transfer of water. Given its notable merits, including a complete salt rejection, less susceptibility to feed concentration, process compactness, and particularly ability to use lowgrade waste heat and solar energy, MD can possibly be an ideal alternative to RO and MSF for small-scale and stand-alone seawater desalination applications in remote coastal regions [2 - 4].

MD processes can be operated in four basic configurations, including direct contact MD, vacuum MD, sweeping gas MD, and air gap MD. Amongst these configurations, air gap MD (AGMD) exhibits the highest process thermal efficiency with the lowest process simplicity. Therefore, AGMD is the most widely used for small-scale seawater MD desalination $[2,3]$.

A major technical challenge to seawater MD application in remote areas is membrane scaling associated with the desire for a high process water recovery (i.e. the volumetric ratio between fresh water product and seawater feed). Membrane scaling results in a reduction in water flux and the quality of fresh water product, membrane damage, and energy consumption increase $[5,6]$.

Given the detrimental effects of membrane scaling, this study aimed to elucidate membrane scaling and cleaning in a seawater AGMD process. The mass transfer coefficient of the AGMD system was experimentally determined. Then, the influence of feed salinity and membrane scaling on water flux was examined. Finally, the efficiency of scaled membrane cleaning with fresh water and vinegar was investigated.

\section{MATERIALS AND METHODS}

The lab-scale AGMD unit used in this study consisted of a plate-and-frame AGMD membrane module, two variable-speed gear pumps for water circulation, a heating element to heat the seawater feed, and a chiller to cool the coolant. Flat-sheet polytetrafluoroethylene (PTFE) membrane provided by Porous Membrane Technology (Ningbo, China) was used in the AGMD membrane module. The membrane had thickness, nominal pore size, and porosity of 60 $\mu \mathrm{m}, 0.2 \mu \mathrm{m}$, and $80 \%$, respectively.

Milli-Q water and seawater were used as the feed. Milli-Q water had electrical conductivity of $45 \pm 5 \mu \mathrm{S} / \mathrm{cm}$. Seawater was collected from Wollongong beach (New South Wales, Australia), and pre-filtered by $0.45 \mu \mathrm{m}$ filter papers. The pre-filtered seawater had total dissolved solids (TDS), electrical conductivity, and $\mathrm{pH}$ of $37,000 \pm 2000 \mathrm{mg} / \mathrm{L}, 52.5 \pm 1.0 \mathrm{mS} / \mathrm{cm}$, and $8.35 \pm$ 0.05 , respectively. The total organic carbon (TOC) concentration of this pre-filtered seawater was less than $2 \mathrm{mg} / \mathrm{L}$. Fresh water and a vinegar purchased from a local super market were used as cleaning agents in AGMD membrane cleaning experiments. As per instructions, the vinegar had acetic acid content of $8.0 \pm 0.5 \%$ and had $\mathrm{pH}$ of $2.55 \pm 0.05$.

AGMD of Milli-Q water was conducted to experimentally determine the process mass transfer coefficient $\left(K_{m}\right)$. The water flux $(J)$ of the process with Milli-Q water was measured at various feed and coolant temperatures. Then, $K_{m}$ could be calculated as: 


$$
K_{m}=\frac{J}{\Delta P}
$$

where $K_{m}$ and $J$ were in $\mathrm{L} \cdot \mathrm{Pa}^{-1} \cdot \mathrm{m}^{-2} \cdot \mathrm{h}^{-1}$ and in $\mathrm{L} \cdot \mathrm{m}^{-2} \cdot \mathrm{h}^{-1}$, respectively; $\Delta P$ was the water vapor pressure difference between the feed and coolant streams (Pa). $\Delta P$ was calculated as:

$$
\Delta P=P_{\text {feed }}^{0}-P_{\text {coolant }}^{0}
$$

The water vapor pressure of the feed and coolant stream was calculated using the Antoine equation:

$$
P^{0}=\exp \left(23.1964-\frac{3816.44}{T-46.13}\right)
$$

where $T$ was the temperature of the stream.

AGMD of seawater was operated in batch mode. Seawater feed $(4 \mathrm{~L})$ was continuously concentrated until the process water flux declined to zero or a process water recovery of $80 \%$ was achieved. Then, membrane cleaning with fresh water or commercial vinegar was initiated. Membrane cleaning was conducted at the same water circulation rates and at room temperature (i.e. $25^{\circ} \mathrm{C}$ ). Membrane cleaning efficiency was assessed based on the restoration of membrane surface hydrophobicity using contact angle measurement, and the visual analysis of membrane surface using scanning electron microscope (SEM) images.

During the AGMD process with seawater, the presence of dissolved salts reduced the water activity of the feed solution, thus lowering its water vapor pressure as expressed in Eq. (4):

$$
P_{\text {feed }}=x_{\text {water }} a_{\text {water }} P^{0}
$$

where $a_{\text {water }}$ was dependent on feed salinity as:

$$
a_{\text {water }}=1-0.5 x_{\text {salt }}-10 x_{\text {salt }}^{2}
$$

where $x_{\text {salt }}$ and $x_{\text {water }}$ were the molar fraction of salt and water in the feed. In addition, concentration polarization effect in AGMD rendered the salt concentration at the membrane surface $\left(C_{m . f}\right)$ higher than that in the bulk feed solution $\left(C_{b . f}\right)$. The polarization effect was dependent on the process water flux as expressed in Eq. (6):

$$
\frac{C_{m . f}}{C_{b . f}}=\exp \left(\frac{J}{k}\right)
$$

where $k$ was the mass transfer coefficient of salt.

\section{RESULTS AND DISCUSSIONS}

\subsection{Mass transfer of AGMD with Milli-Q water}

Increasing feed-coolant temperature while maintaining a constant temperature difference $(\Delta T)$ between the feed and coolant stream resulted in an increase in water flux but a decrease in mass transfer coefficient (Figure 1). The increase in water flux at higher feed-coolant temperature could be attributed to the exponential relationship between water vapor pressure and temperature as demonstrated in Eq. (3). Indeed, elevating feed-coolant temperature from 35-25 
to $60-50{ }^{\circ} \mathrm{C}$ increased $\Delta P$ from 1.28 to $3,68 \mathrm{kPa}$, thus increasing water flux from 2.5 to $5 \mathrm{~L} . \mathrm{m}^{-}$ ${ }^{2} \cdot \mathrm{h}^{-1}$. By contrast, $K_{m}$ decreased from $1.8 \times 10^{-3}$ to $1.3 \times 10^{-3} \mathrm{~L} \cdot \mathrm{Pa}^{-1} \cdot \mathrm{m}^{-2} \cdot \mathrm{h}^{-1}$ (Figure 1 ). The decrease in $K_{m}$ with increased feed-coolant temperature demonstrated the influence of temperature polarization on water flux of AGMD. The values of $K_{m}$ were determined using the measured temperatures of the feed and the coolant streams instead of temperatures at the feed membrane surface and at the condenser surface. Temperature polarization effect rendered the temperature difference between the feed membrane surface and the condenser surface (i.e. the actual driving force of the process) smaller than that between the feed and coolant stream $(\Delta T)$, thus reducing water flux and hence $K_{m}$ of the process. Increasing feed-coolant temperature elevated water flux and therefore magnified temperature polarization effect.

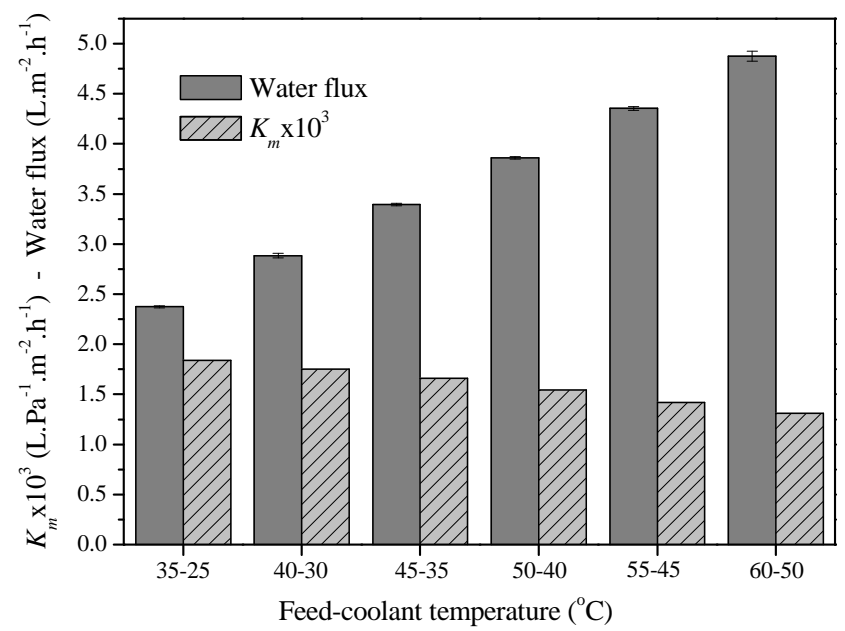

Figure 1. Experimentally measured water flux and mass transfer coefficient $\left(K_{m}\right)$ during AGMD process with Milli-Q water at various feed-coolant temperature, a constant $\Delta T$ of $10^{\circ} \mathrm{C}$, and water circulation rate

$F_{\text {feed }}=F_{\text {coolant }}=0.5 \mathrm{~L} / \mathrm{min}$. Error bars represent the standard deviation of water flux measurements.

\subsection{AGMD of seawater}

The influence of feed salinity on water flux and distillate conductivity during AGMD of seawater is demonstrated in Figure 2. Increasing feed salinity during the concentration of seawater led to a reduction in water flux of AGMD. This was attributed to the decrease in water activity and thus the reduction in water vapor pressure of the feed stream with increased feed salinity as expressed in Eqs. (4-5) [7].

Compared to simulated water flux, the experimentally measured flux decreased more as the seawater feed was concentrated (Figure 2). The deviation between the experimentally measured and the simulated flux was because of concentration polarization effect and membrane scaling. The simulation of water flux using the $K_{m}$ values obtained during AGMD of Milli-Q water excluded the influence of concentration polarization effect. Concentration polarization effect caused the salt concentration at the membrane surface higher than that in the bulk feed solution, thus reducing water flux. Operating AGMD at higher feed-coolant temperature and hence higher water flux aggravated concentration polarization as expressed in Eq. (6) [7]. Therefore, the deviation between the measured and simulated water flux was more at feed-coolant temperature of $60-50{ }^{\circ} \mathrm{C}$ compared to that at $35-25^{\circ} \mathrm{C}$ (Figure 2). 


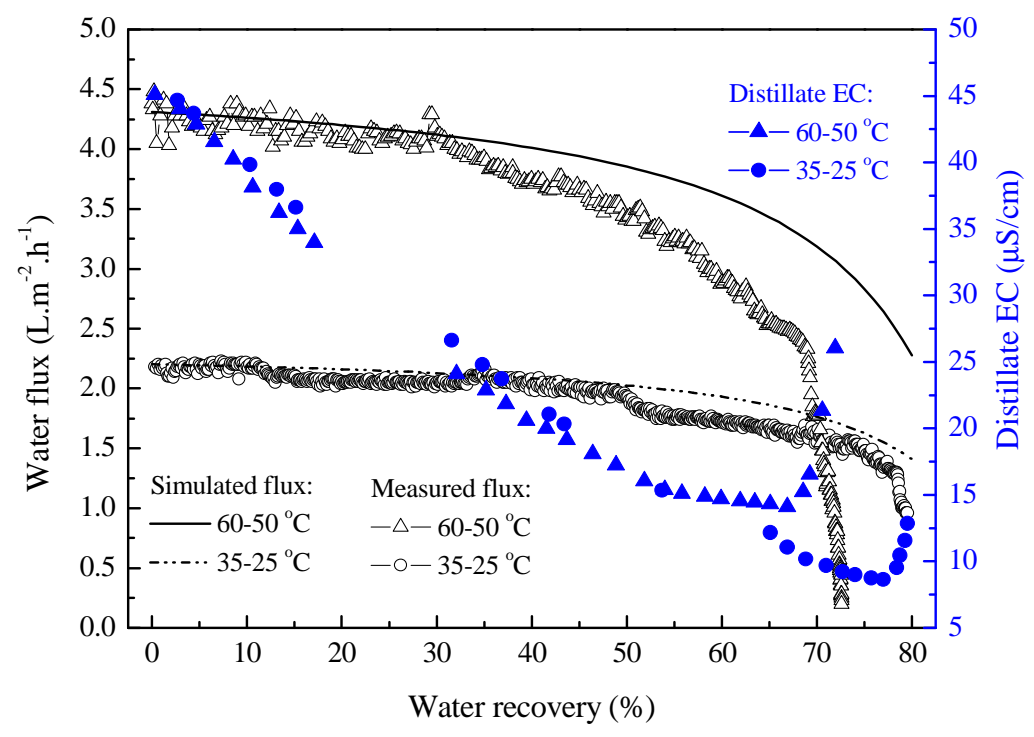

Figure 2. Simulated and experimentally measured water flux and distillate electrical conductivity (EC) as functions of process water recovery during AGMD with seawater. Water circulation rate

$$
F_{\text {feed }}=F_{\text {coolant }}=0.5 \mathrm{~L} / \mathrm{min} \text {. }
$$

Membrane scaling caused by the precipitation of sparingly soluble salts (e.g. $\mathrm{CaSO}_{4}$ and $\mathrm{MgSO}_{4}$ ) in seawater further reduced the measured flux (Figure 2). As the seawater feed was concentrated, the concentration of these salts exceeded their saturation limits. Concentration polarization effect further increased the supersaturation of the salts at the membrane surface, leading to the formation of scale layers on the membrane. The scale layers promoted temperature and concentration polarization effects, and reduced water vapor pressure at the membrane surface and the active membrane area for water evaporation $[8,9]$. Therefore, water flux rapidly decreased from $2.5 \mathrm{~L} \cdot \mathrm{m}^{-2} \cdot \mathrm{h}^{-1}$ to almost zero and from 1.5 to $1.0 \mathrm{~L} \cdot \mathrm{m}^{-2} \cdot \mathrm{h}^{-1}$ as the process water recovery exceeded $70 \%$ and $75 \%$ at feed-coolant temperature of $60-50$ and $35-25{ }^{\circ} \mathrm{C}$, respectively (Figure 2).

Membrane scaling also resulted in decline in distillate quality (Figure 2). At the beginning of the AGMD process, the electrical conductivity of the distillate gradually decreased. The gradual decrease in distillate conductivity before membrane scaling demonstrated the ability of AGMD for pure water production from seawater. Indeed, distillate with conductivity as low as $10 \mu \mathrm{S} / \mathrm{cm}$ was obtained from seawater. When membrane scaling occurred, the scale layers altered the hydrophobicity of the membrane surface [10,11], leading to partial intrusion of seawater through the membrane pores. Consequently, distillate conductivity started increasing following the formation of scale layers on the membrane (Figure 2).

Operating feed-coolant temperature influenced not only the water flux but also membrane scaling in AGMD of seawater. Increasing feed-coolant temperature from $35-25$ to $60-50{ }^{\circ} \mathrm{C}$ doubled water flux, and at the same time escalated membrane scaling. Membrane scaling occurred at a lower water recovery when operating at $60-50{ }^{\circ} \mathrm{C}$ compared to that at $35-25^{\circ} \mathrm{C}$ (Figure 2). The operating temperature also affected the efficiency of subsequent membrane cleaning as will be discussed in the next section. 


\subsection{Efficiency of membrane cleaning}

The efficiency of membrane cleaning could be evaluated by the restoration of membrane surface hydrophobicity. Compared to fresh water, vinegar demonstrated a superior membrane cleaning efficiency under the same cleaning conditions (i.e. water circulation rates, temperature, and cleaning duration) (Figure 3). Given its hydrophobic nature, the contact angle of the virgin membrane used in this study was $130^{\circ}$. The scale layers formed at the membrane rendered its surface so hydrophilic that its contact angle could not be determined. Cleaning the scaled membrane with vinegar effectively removed scalants from the membrane surface, thus returning it to a hydrophobic condition (i.e. contact angle of the scaled membrane at $60-50$ and $35-25{ }^{\circ} \mathrm{C}$ increased to $120^{\circ}$ and $125^{\circ}$, respectively, after cleaning with vinegar). It is worth noting that the vinegar contained a high content of acetic acid that might have increased the solubility and thus the removal of the sparingly soluble salts from the membrane surface. The slight decrease in contact angle of the vinegar cleaned membrane compared to the virgin membrane was expected because deterioration in membrane hydrophobicity has been reported in DCMD process with only pure water [5]. Cleaning the scaled membrane with fresh water was unable to remove all scale deposits from the membrane surface (i.e. confirmed by SEM images of the scaled membrane surfaces). The scales remained on the membrane surface significantly reduced its hydrophobicity. Thus, the contact angle of the scaled membrane surface following fresh water cleaning was far below $90^{\circ}$ (Figure 3 ).

The operating feed-coolant temperature slightly affected the efficiency of subsequent scaled membrane cleaning. Cleaning with both vinegar and fresh water was more efficient for the membrane scaled at $35-25^{\circ} \mathrm{C}$ compared to that at $60-50{ }^{\circ} \mathrm{C}$ (Figure 3). As discussed above, membrane scaling at $60-50{ }^{\circ} \mathrm{C}$ was more severe than at $35-25{ }^{\circ} \mathrm{C}$, resulting in thicker and possibly more compacted scale layers at $60-50{ }^{\circ} \mathrm{C}$ compared to $35-25^{\circ} \mathrm{C}$. The morphology of the scale layers appeared to exert an effect on the efficiency of the subsequent membrane cleaning.

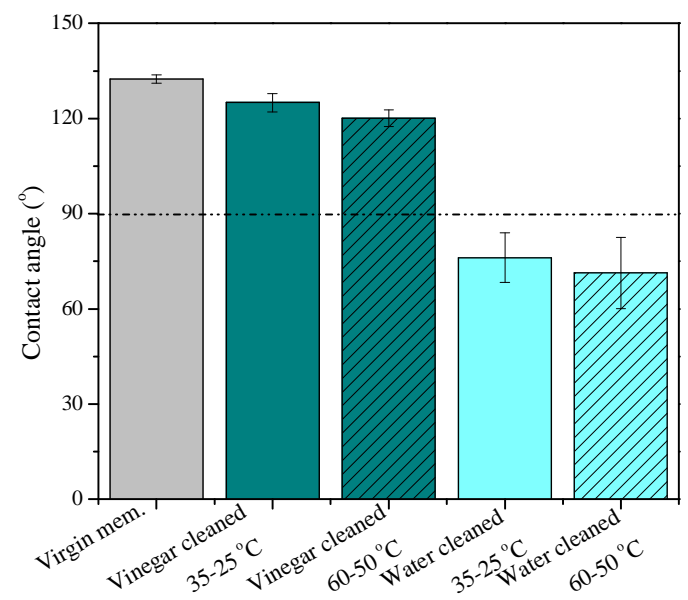

Figure 3. Contact angles of the virgin membrane and the scaled membranes at 35-25 and $60-50{ }^{\circ} \mathrm{C}$ after cleaning with vinegar and fresh water. Error bars represent the standard deviation of 5 repeated measurements.

The results reported here have significant implications for pilot or small-scale seawater AGMD application, in which membrane modules with long membrane channels are employed. 
Along the membrane channels, the feed temperature significantly decreases from 70 to $35^{\circ} \mathrm{C}$, and the coolant temperature increases from 25 to $60{ }^{\circ} \mathrm{C}[12,13]$. The change in feed-coolant temperature will result in an uneven distribution of water production along the membrane channels - more distillate is obtained at the higher temperature end of the membrane module compared to the low temperature end. Also because of the uneven distribution of feed-coolant temperature, membrane scaling will occur at the high temperature membrane area before the low temperature one. Finally, when membrane scaling occurs, it will be harder to clean the membrane area scaled at higher temperature compared to that at low temperature. The scale remnants on the membrane after cleaning will act as crystal nuclei, and thus accelerating membrane scaling in the next seawater AGMD cycle [6]. As a result, repetitive membrane scaling and cleaning in AGMD of seawater will inevitably lead to deterioration in process performance. In this context, effective scaling prevention techniques, including but are not limited to anti-scalant addition [14 - 16], utilization of ultrasonic and gas bubbling [17, 18], or process optimization $[9,19,20]$, are highly recommended.

\section{CONCLUSIONS}

AGMD of an actual seawater feed were investigated. The experimental results demonstrate a profound influence of feed salinity and operating temperature on water flux, scaling behavior, and the efficiency of subsequent membrane cleaning. Feed salinity reduced the water flux of the AGMD process with seawater compared to that with fresh water, particularly at higher operating temperatures due to the aggravated polarization effects. Increasing feed-coolant temperature from $35-25$ to $60-50{ }^{\circ} \mathrm{C}$ doubled water flux but also escalated membrane scaling during seawater desalination with AGMD. At feed-coolant temperature of $60-50{ }^{\circ} \mathrm{C}$, membrane scaling occurred at a lower water recovery compared to that at $35-25{ }^{\circ} \mathrm{C}$. The efficiency of membrane cleaning with fresh water and vinegar was also lower for the membrane scaled at $60-50{ }^{\circ} \mathrm{C}$ compared to at $35-25{ }^{\circ} \mathrm{C}$. Vinegar cleaning demonstrated a superior efficiency to fresh water cleaning. Given the accessibility to vinegar at household level, membrane cleaning using vinegar can be a practical scaling control method for small-scale seawater MD desalination applications.

\section{REFERENCES}

1. Elimelech M. and Phillip W. A. - The Future of Seawater Desalination: Energy, Technology, and the Environment, Science 333 (2011) 712-717.

2. Zaragoza G., Ruiz-Aguirre A., and Guillén-Burrieza E. - Efficiency in the use of solar thermal energy of small membrane desalination systems for decentralized water production, Applied Energy 130 (2014) 491-499.

3. Chafidz A., Al-Zahrani S., Al-Otaibi M. N., Hoong C. F., Lai T. F., and Prabu M. Portable and integrated solar-driven desalination system using membrane distillation for arid remote areas in Saudi Arabia, Desalination 345 (2014) 36-49.

4. Koschikowski J., Wieghaus M., and Rommel M. - Solar thermal-driven desalination plants based on membrane distillation, Desalination 156 (2003) 295-304.

5. Ge J., Peng Y., Li Z., Chen P., and Wang S. - Membrane fouling and wetting in a DCMD process for RO brine concentration, Desalination 344 (2014) 97-107. 
6. Duong H. C., Duke M., Gray S., Cath T. Y., and Nghiem L. D. - Scaling control during membrane distillation of coal seam gas reverse osmosis brine, Journal of Membrane Science 493 (2015) 673-682.

7. Alkhudhiri A., Darwish N., and Hilal N. - Membrane distillation: A comprehensive review, Desalination 287 (2012) 2-18.

8. Wang L., Li B., Gao X., Wang Q., Lu J., Wang Y., and Wang S. - Study of membrane fouling in cross-flow vacuum membrane distillation, Separation and Purification Technology 122 (2014) 133-143.

9. Nghiem L. D. and Cath T. - A scaling mitigation approach during direct contact membrane distillation, Separation and Purification Technology 80 (2011) 315-322.

10. Tijing L. D., Woo Y. C., Choi J. S., Lee S., Kim S. H., and Shon H. K. - Fouling and its control in membrane distillation - A review, Journal of Membrane Science 475 (2015) 215-244.

11. Warsinger D. M., Swaminathan J., Guillen-Burrieza E., Arafat H. A., and Lienhard V. J. H. - Scaling and fouling in membrane distillation for desalination applications: A review, Desalination 356 (2014) 294-313.

12. Duong H. C., Cooper P., Nelemans B., Cath T. Y., and Nghiem L. D. - Evaluating energy consumption of membrane distillation for seawater desalination using a pilot air gap system, Separation and Purification Technology 166 (2016) 55-62.

13. Duong H. C., Chivas A. R., Nelemans B., Duke M., Gray S., Cath T. Y., and Nghiem L. D. - Treatment of RO brine from CSG produced water by spiral-wound air gap membrane distillation - A pilot study, Desalination 366 (2015) 121-129.

14. He F., Sirkar K. K., and Gilron J. - Effects of antiscalants to mitigate membrane scaling by direct contact membrane distillation, Journal of Membrane Science 345 (2009) 53-58.

15. Zhang P., Knötig P., Gray S., and Duke M. - Scale reduction and cleaning techniques during direct contact membrane distillation of seawater reverse osmosis brine, Desalination 374 (2015) 20-30.

16. Peng Y., Ge J., Li Z., and Wang S. - Effects of anti-scaling and cleaning chemicals on membrane scale in direct contact membrane distillation process for RO brine concentrate, Separation and Purification Technology 154 (2015) 22-26.

17. Hou D., Wang Z., Li G., Fan H., Wang J., and Huang H. - Ultrasonic assisted direct contact membrane distillation hybrid process for membrane scaling mitigation, Desalination 375 (2015) 33-39.

18. Chen G., Yang X., Wang R., and Fane A. G. - Performance enhancement and scaling control with gas bubbling in direct contact membrane distillation, Desalination 308 (2013) 47-55.

19. Duong H. C., Cooper P., Nelemans B., and Nghiem L. D. - Optimising thermal efficiency of direct contact membrane distillation via brine recycling for small-scale seawater desalination, Desalination 374 (2015) 1-9.

20. Hickenbottom K. L. and Cath T. Y. - Sustainable operation of membrane distillation for enhancement of mineral recovery from hypersaline solutions, Journal of Membrane Science 454 (2014) 426-435. 